\title{
Smartphone Controlled Spy Robot with Video Transmission and Object Collector
}

\author{
ASM Shamim Hasan ${ }^{\text {a }}$, Md. Khalid Hossain Jewel ${ }^{\mathrm{a}}$, Md. Niaz Mostakim ${ }^{\mathrm{a}}$, Nabil Hossain \\ Bhuiyan $^{\mathrm{a}}$, M. K. Rahman ${ }^{\mathrm{a}}$, Sheikh Dobir Hossain ${ }^{\mathrm{b}}$, Md. Khalid Hossain ${ }^{\mathrm{c}}$ \\ ${ }^{a}$ Dept. of Electrical and Electronic Engineering, Islamic University, Bangladesh \\ ${ }^{b}$ Dept. of Physics, Jessore University of Science and Technology, Jessore-7408, Bangladesh \\ ${ }^{c}$ Institute of Electronics, Atomic Energy Research Establishment, Savar, Dhaka-1349, Bangladesh
}

Received: 30 December 2016; Accepted: 13 February 2017; Published: 08 November 2017

\begin{abstract}
Android, an operating system developed by Google for smartphones, tablets and such type of touchscreen phones. Android app is a software running on Android platform. Typically an app is designed for specific purpose on Android platform such as smartphones and tablets. In this work a designing and implementing process of an Android based spy robot is described. An Android based application, RC Bluetooth controller is used to control in this spy robot. This robot can be controlled with the help an app of Android phones. Arduino based microcontroller is used for instruction processing and giving proper instructions. Bluetooth technology is used to interface between Arduino and Android. A hand for collecting and holding objects and a camera for live video steaming is used to observe any object $\&$ movement of robot. This robot can move to any place and perform smartly within Bluetooth network range.
\end{abstract}

Index Terms: Intelligence, Robot, Camera, Bluetooth, Servo motor.

(C) 2017 Published by MECS Publisher. Selection and/or peer review under responsibility of the Research Association of Modern Education and Computer Science

\section{Introduction}

Robot is a kind of machine that performs very complex \& multiple tasks by the instructions that is stored on a programmable device automatically or by giving instructions externally [1]. It needs an interfacing device such as Bluetooth, Wi-Fi, ZigBee etc. for external controlling. In this work our concern is to build a spy robot i.e. such type of robot that can remain hidden and do the work without notifying any human being. It can be

\footnotetext{
* Corresponding author

E-mail address: khalid.baec@yahoo.com
} 
used as an information collector, object collector and for that type of works. This robot can work automatically or can be controlled by smartphones over Bluetooth, a kind of wireless personal network which can be used to interface between microcontroller and smartphone. In smartphone an Android app is used to send data to the microcontroller that works as given instructions burned to it. Remote controlled spy robots are also available that use RF signal and works properly [2]. In this system a camera is also used. Researchers have developed many robots in this arena of robotics i.e. Spy robots. Ritika Pahuja et. al has proposed and implemented an Android based Bluetooth UART interfacing robot [3]. They have used 8051 microcontrollers, HC-06 Bluetooth module, and Bluetooth RC car app to implement that robot. Mrumal.K.Pathak et. al has proposed Android based robot controlled by using Bluetooth from Android phone [4]. Aniket R. Yeole et al has developed a smartphone controlled robot [5]. In this work we have used Atmega328p microcontroller, JY MCU BT HC-06 Bluetooth and ultrasonic sensor. That work deals with the system that can detect obstacles. If the sonar sensor detects the echo signal then it automatically stops. Also, it is controlled by Bluetooth signals such as numerical values. This robot can be used as a surveillance robot. Dipak Gonde et al Give a concept and develop a robot that is controlled by smart phone [6]. That proposed system is constructed using smartphone, two apps and sensor to measure distance from obstacle. This system works properly. One app send text to another app. Second app send signal to the controller. There has a sonar to detect obstacle. A very outstanding concept for controlling a robot in three different ways [7]. Arita De et al has developed and implemented this robot. They use direction control, voice control and tilt control to control robot. That app is develop by them. They used accelerometer sensor from Android phone to use the tilt option in the app. An image transferring robot is designed by Saravana Kumar K et al [8]. In this robot Android mobile is used to control it. The App is also developed by them. Android webcam is used to capture image and image is uploaded in the server. An app IP webcam display this images. Prof. Y. M. Naik et al has suggested and implemented an Android controlled spyrobot [9]. They had used two smartphones, one is placed on robot and other is used as a controller. The first phone can capture image in different angle when commanded and sends them to a corresponding email id. Simple Android phone control robot has been implemented by Rahul Kumar et al [10]. In that work, an Android app with button is used to control the robot. Interfacing device Bluetooth is used in this system. Here also numerical values are used to control the robot. Aaruni Jha et.al implement a night version camera based spy robot [11]. In that robot, RF transceiver is used to transmit and receive the signals. Wireless CCD camera for this purpose. That camera can send audio and video. Premangshu Chanda et al has implemented a gesture controlled robot [12]. In this robot accelerometer sensor is used from smart phone.

From above descriptions the difference in our work is this our robot has a hand that it can collect things and transmits video signal to the television display. This robot is also controlled by using DMF i.e. key button of any phone. The main objectives of this system [13-17] is that any object can be collected by this from any dangerous area where human be faced a lot of problem. It can also be used to transmit video from dangerous places and can be controlled remotely from distant places. This robot can be used as a spy robot to collect any information, photos, videos or any object from any dangerous areas. The robot can also be used in any rescue missions. As the size of the robot is compact it is very easy to send anywhere without notifying anyone.

\section{Proposed System}

The block diagram of this proposed system is shown in Fig.1. In this system the microcontroller is the heart. It is controlled from outside device i.e. Android phone which communicates with microcontroller via Bluetooth personal network. An Android app is used to control it. Here DC gear motor is used to move the system back and forth and also towards move any direction. Two servo motors have been used to this system. One servo motor is used for the hand that collects objects from any place and second servo motor is used for moving the camera.

Here, an Android smart phone acts as a remote controller device for controlling the movement of the robot. An Android application is used for this purpose. The application supports only the 2.2 and above versions of Android Operating Systems. The Bluetooth module acts as an interface between Smartphone and 
microcontroller. HC-05 Bluetooth module is used for this system. In this systems master is the smartphone and slave is the Bluetooth module. Bluetooth module fetches the commands given by the smartphone to the microcontroller. The microcontroller acts as the brain of the robot. The robots movement is decided by the microcontroller. In this system contains microcontroller named Arduino Uno. The microcontroller will be programmed with the help of the Embedded $\mathrm{C}$ programming. Arduino has its own programming environment through which the microcontroller can be programed. For travelling purpose this system uses DC motor. It generates high amount of power and torque. A motor driver is used to control the DC motor which is connected to the microcontroller and the Bluetooth module is connected to the same. In this proposed system, a rechargeable battery is used to supply power to the electronic components of the system. Mainly the microcontroller and DC motor will be in need of power supply. Fig.1 shows the block diagram of the interface of the robot.

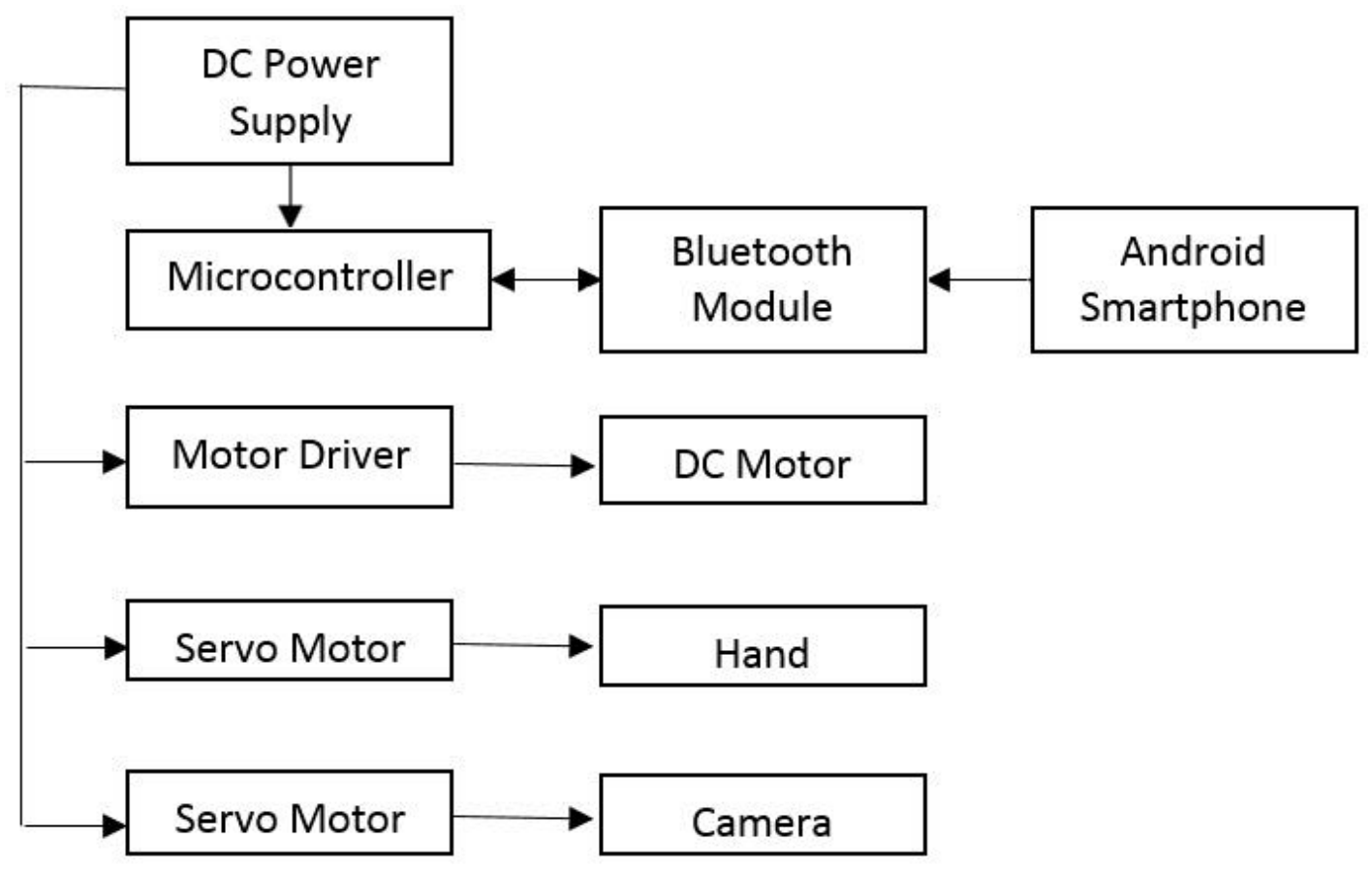

Fig.1. Block Diagram of Proposed System

\section{System Designing}

The designing and architecture of the robot is kept as simple as possible. Here, some electronic components and some modules have been used to construct the robots circuit. Sections 4 bellow has been listed with the hardware's' that is present in the system. From the flow chart (Fig.2) at first the Bluetooth device is detected by the smartphone and connect it to this phone. Then the Bluetooth module waits for serial data. When the serial data is available then the microcontroller read these serial data and work as the burned to it. When the serial data is not available then the microcontroller does not response. The body of the robot has been made using readymade robotic kits, screws and gear motors wheel. 


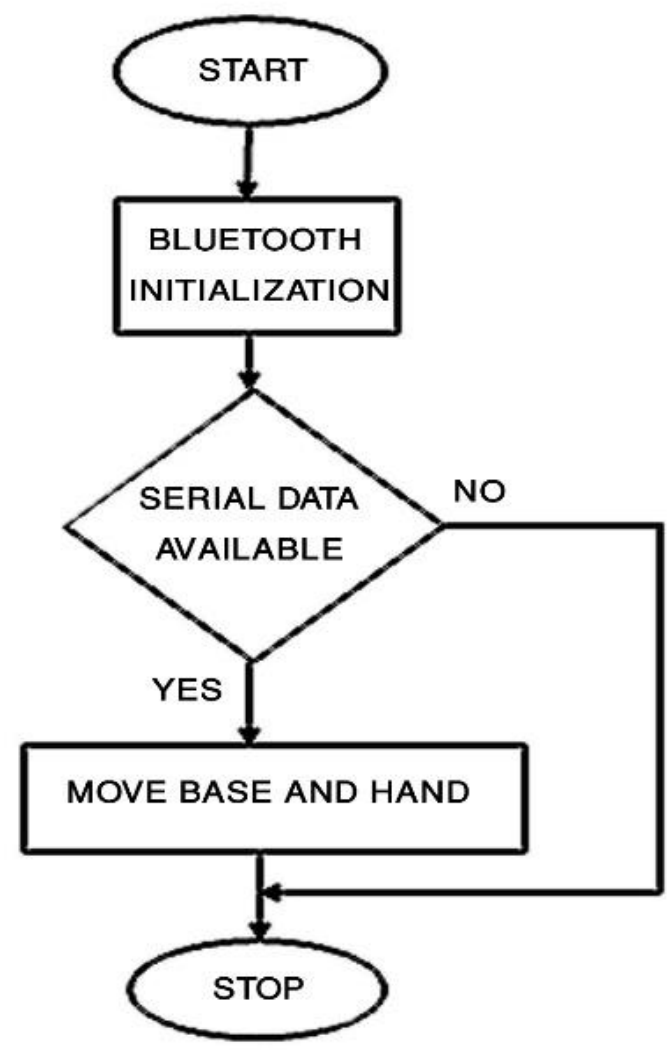

Fig.2. Flowchart of Proposed Home Security System by Obstacle Detection.

\section{Hardware}

The hardware designing of the robot consist of 2 sections. The first one is the electronic section and another one is the body section. The electronic section is consist of some well-designed circuitries that contains some electronic components and modules which has been listed below with their pictures in the fig.3. The hardware section consist of robotic kits and gear motor wheels.

The proposed system consists of following components:

a. Robotic kits

b. Servo motor (Metal Gear)

c. Servo motor SG90

d. Battery

e. Bluetooth module (HC-05)

f. Microcontroller (Atmel ATmega 328p)

g. Camera

h. Motor driver. 


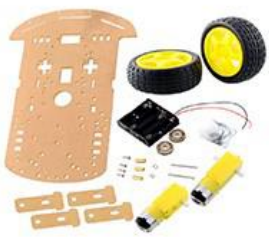

(a)

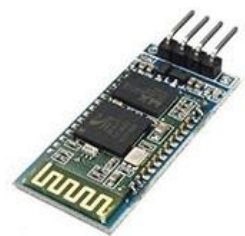

(e)

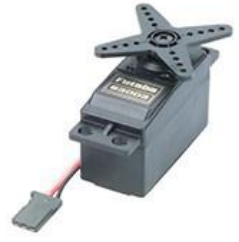

(b)

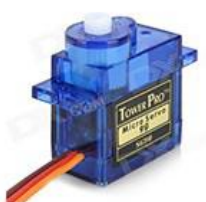

(c)

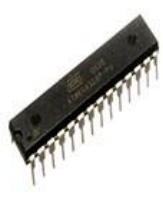

(f)

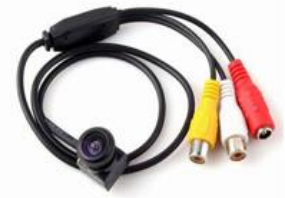

(g)
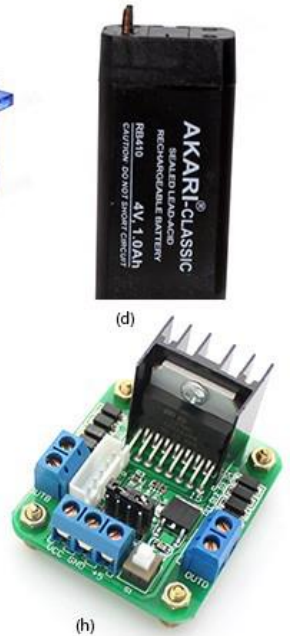

Fig.3. Required components (a) Robot kit, (b) Servo Motor (metal gear), (c) Servo Motor (SG90), (d) Battery, (e) Bluetooth Module, (f)ATmega 328p Microcontroller, (g) Camera and (h) Motor Drive Module

The hardware section the robot has been described below:

(a) ROBOT: The robot [18] consists an ATmega 328P microcontroller that has the embedded c code dumped into it.

(b) CONTROLLER: The controller [19] is an Android cell-phone. The cell phone is connected to the Bluetooth in the robot. This Bluetooth establishes a communication channel between the controller and the robot. The RC Controller .apk file i.e. the target file is stored into the cell-phone. When it runs then the GUI i.e. the screen on the cell phone occurs and the user gives gestures. These gestures are converted into analogue signals and transmits to the robot. Here, they converted into digital signals and the microcontroller code starts executing and the robot moves according to the gestures.

(c) CAMERA: A camera is attached to it. This camera can rotate up to 180 degree to capture video and transmits it by the wireless transmitter to the receiving centre.

(d) HAND: A hand is also attached to the robot to pick up a sample or object up to 50gm now. All of the above-mentioned components have mounted on the skateboard as mentioned in the system architecture. DC motor is $600 \mathrm{rpm} \mathrm{[20]} \mathrm{and} 11 \mathrm{~nm}$ motor which will be able to drive about 8-9 $\mathrm{kg}$ weight. A motor driver is used to control the DC motors, it can handle up to 24 volts and 20 amperes made up using Hbridge architecture. The microcontroller is the brain of the robot and is able to connect the smartphone through the Bluetooth module. The motor belt driver is used to connect the wheels of the skateboard and the dc motor through driving cog. The entire electronic component except the motor and belt will be kept in Electronic component case. The Android smartphone will act as a remote controller of the robot. Acceleration and de-acceleration of the robot can be done with the help of the Android smartphone. All Electronic and mechanical component will be mounted on the skateboard. To provide mechanical strength to the board for bearing extra weight an elastic property using aluminum covering over the joined with resin is provided. This will increase the physical strength of the skate board.

\section{Software Simulation Circuit}

After completing the system design and hardware selection schematic circuit is drawn in Proteus simulation software. In Proteus simulation, circuit works properly. When these circuits all element and parts work 
accurately then this circuit is implemented that is shown in fig. 5. The schematic circuit is shown in fig. 4 .

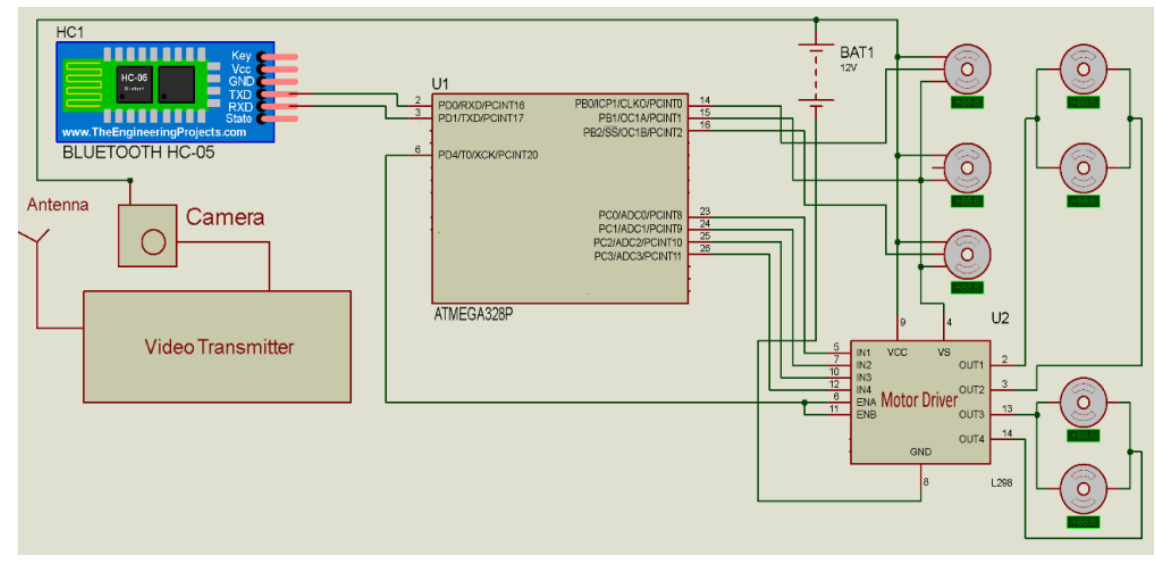

Fig.4.Circuit Diagram of Spy Robot

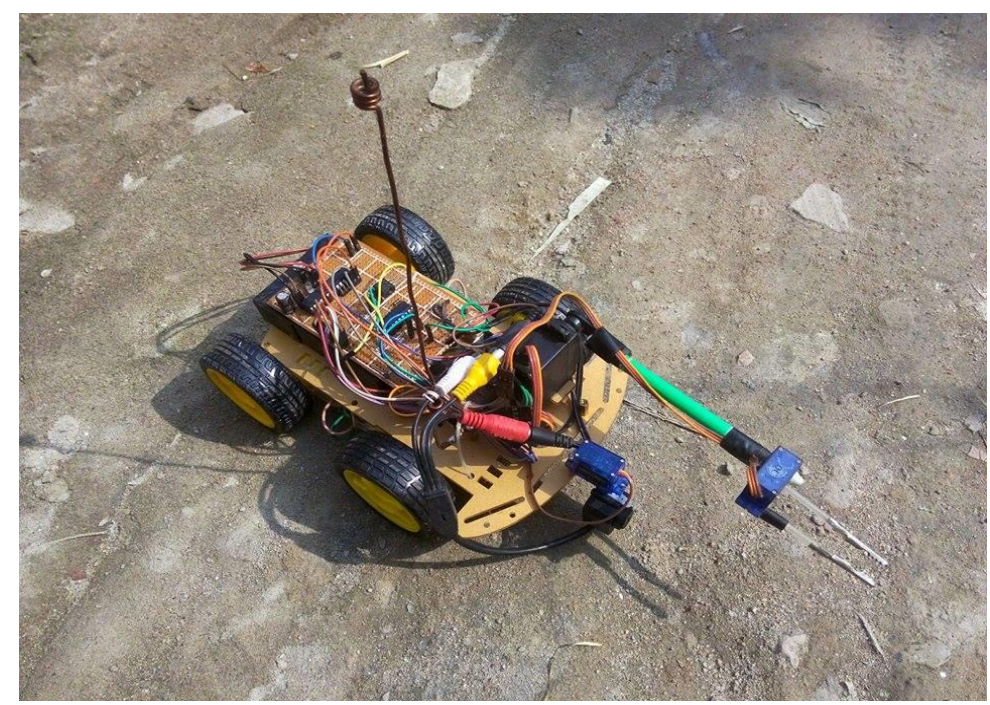

Fig.5. Implemented Circuit

\section{Result and Discussion}

The implemented system is shown in Fig.5. In this system instructions are given to the microcontroller with the help of a smartphone through Bluetooth interfacing. Within 100 meters the instructions from the smartphone reach to the microcontroller very accurately. This system can move towards any direction properly. The wireless camera to transmit [21] video has worked as the instruction given to it. The video transmission and all the sensors in this system are performing accurately. The transmitting signal's quality is good. At this time this spy robot can pick up to $150 \mathrm{gm}$ object. While developing this system some problems have been faced to control servo motor and interfacing Bluetooth. All that problems has been solved by modifying the circuit and the programming code. Therefore, at present it works properly. We have measured the current consumption as well the battery backup. Here, the gear motors consumes around $300 \mathrm{mAh}$ currents individually. Therefore it 
consumes around $1200 \mathrm{mAh}$ currents altogether as there are four motors in the system. The Servo motors consumes $500 \mathrm{mAh}$ (metal gear) and $250 \mathrm{mAh}$ (SG90) currents individually. The microcontroller, Bluetooth module and other circuits consumes around $300 \mathrm{mAh}$ currents altogether. Considering some losses around $2600 \mathrm{mAh}$ currents is been consumed by the system. Here, we have installed batteries with the current rating of $3000 \mathrm{mAh}$ and 5 volts. Therefore it can run about 1 hour or slightly more depending on the use with one charge.

\section{Conclusions}

The proposed system shows how the Android smartphone can be used as remote controller for robot and various embedded technologies with the help of the Bluetooth technology. It could be improved by adding WiFi module for large area coverage. The proposed system also shows that how a robot can be used for spy \& rescuing purpose. The operating system of the smartphone is Android, and we can develop effective remote controller program and by using Wi-Fi wireless network, which makes it simple and convenient to control the robot. If the motor wheel is changed and replaced by a chain wheel than it can move anywhere at any rough condition.

\section{References}

[1] Thomas R. Kurfess, "Robotics and Automation Handbook", 2004, Taylor \& Francis Group, CRC Press, UK.

[2] Balakrishnan M, Gowthaman S, Kumaran SJ, Sabhapathy GR. A smart spy robot charged and controlled by wireless systems. InInnovations in Information, Embedded and Communication Systems (ICIIECS), 2015 International Conference on 2015 Mar 19 (pp. 1-4). IEEE.

[3] Pahuja R, Kumar N. Android Mobile Phone Controlled Bluetooth Robot Using 8051 Microcontroller. International Journal of Scientific Engineering and Research (IJSER). 2014 Jul; 2(7).

[4] Pathak MK, Khan J, Koul A, Kalane R, Varshney R. Related Items.

[5] Yeole AR, Bramhankar SM, Wani MD, Mahajan MP. Smart phone controlled robot using ATMEGA328 microcontroller. Int. J. Innovative Res. Comput. Commun. Eng. 2015 Jan; 3:191-7.

[6] Gonde D, Jadhav S, Lokhande M. Robot Control using Android Smartphone. Journal of Android and IOS Applications and Testing. 2016 May 6; 1(1).

[7] Dey A, Pal A, Nandi S, Roy L. Three way controlled Android Smartphone based robotic vehicle via Bluetooth.

[8] Saravana Kumar K, Mannu Nayyar,Reshma M, Biju Joseph" Android controlled robot with image transfer". International Journal of Advanced Multidisciplinary Research 2(3): (2015): 98-102.

[9] Naik YM, Deshpande CM, Shah RR, Kulkarni RR. ANDROID CONTROLLED SPY-ROBOT. International Journal of Software and Web Sciences. 2013:54-7.

[10] Rahul Kumar, Ushapreethi P, Pravin R. Kubade,Hrushikesh B. Kulkarni "Android Phone controlled Bluetooth Robot" International Research Journal of Engineering and Technology (IRJET) Volume: 03 Issue: 04 | Apr-2016.

[11] Jha A, Singh A, Turna R, Chauhan S. War Field Spying Robot with Night Vision Camera. Journal of Network Communication and Emerging Technology. 2015 May; 2(1).

[12] Chanda P, Mukherjee PK, Modak S, Nath A. Gesture Controlled Robot using Arduino and Android. International Journal. 2016 Jun; 6(6).

[13] Ramani R, Valarmathy S, SuthanthiraVanitha N, Selvaraju S, Thiruppathi M, Thangam R. Vehicle tracking and locking system based on GSM and GPS. International Journal of Intelligent Systems and Applications. 2013 Aug 1; 5(9):86.

[14] Shome S, Bera RN. SMS Tracking System with Doppler Radar to Enhance Car Security for Intelligent Transport System. International Journal of Intelligent Systems and Applications. 2015 Jan 1; 7(2):50. 
[15] Mohamed HA. A Proposed Model for Radio Frequency Systems to Tracking Trains via GPS (The Study for Egyptian National Railways). International Journal of Intelligent Systems and Applications. 2014 Mar $1 ; 6(4): 76$.

[16] Kaven Raj S/O Manoharan, Siew-Chin Chong, Kuok-Kwee Wee, "A Solution for Android Device Misplacement through Bluetooth-enabled Technology", International Journal of Intelligent Systems and Applications(IJISA), IJISA Vol. 7, No. 11, October 2015.

[17] Robinson P. Paul, Ghansyam B. Rathod, Vishwa R. Trivedi, Punit V. Thakkar," Persistence of Vision control using Arduino", International Journal of Intelligent Systems and Applications(IJISA), IJISA Vol. 6, No. 1, December 2013.

[18] Fatma Boufera, Fatima Debbat, Lounis Adouane, Mohamed Faycal Khelfi," Mobile Robot Navigation using Fuzzy Limit-Cycles in Cluttered Environment”, International Journal of Intelligent Systems and Applications(IJISA), IJISA Vol. 6, No. 7, June 2014.

[19] Kanza Zafar, Ibrahim M. Hussain, "Rope Climbing Robot with Surveillance Capability", International Journal of Intelligent Systems and Applications (IJISA, IJISA Vol. 5, No. 9, August 2013.

[20] Gopal Krishan, V. R. Singh, "Motion Control of Five Bar Linkage Manipulator Using Conventional Controllers Under Uncertain Conditions", International Journal of Intelligent Systems and Applications(IJISA), IJISA Vol. 8, No. 5, May 2016.

[21] Azita Yazdanpanah, Farzin Piltan, Ali Roshanzamir, Marjan Mirshekari, Narges Gholami mozafari," Design PID Baseline Fuzzy Tuning Proportional- Derivative Coefficient Nonlinear Controller with Application to Continuum Robot", International Journal of Intelligent Systems and Applications(IJISA), IJISA Vol. 6, No. 5, April 2014.

\section{Authors' Profiles}

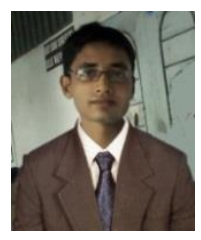

ASM Shamim Hasan has received his B.Sc. (Hons) and M.Sc. degree from the dept. of Electrical and Electronic Engineering of Islamic University, Kushtia-7003, Bangladesh. His current interest includes microcontroller based system design, electronics system design and development, MATLAB based system development, MATLAB programming interface with microcontroller and communication engineering.

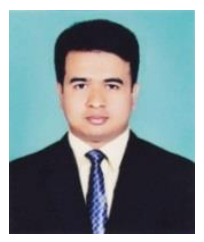

Md. Khalid Hossain Jewel received his Bachelor's and Master's degree from the dept. of Applied Physics, Electronics \& Communication Engineering of Islamic University, Kushtia7003, Bangladesh in 2004 and 2005 respectively. In 2015 he completed his M.Phil. degree in wireless communication. He is an associate professor of the department of Electrical and Electronic Engineering in Islamic University, Bangladesh and currently he is involved as a $\mathrm{PhD}$ research fellow in Satellite Communication in the University of Science and Technology of China (USTC). His research interest includes Satellite Communication, Ad-hoc wireless communication, intelligent systems design, cellular mobile communication and optical fiber communication.

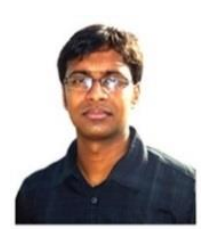

Md. Niaz Mostakim has received his B.Sc. (Hons) and M.Sc. degree from the dept. of Electrical and Electronic Engineering of Islamic University, Kushtia-7003, Bangladesh. His current interest includes microcontroller based system design, electronics system design and development, MATLAB based system development, MATLAB programming interface with microcontroller and communication engineering. He received University Merit Scholarship for his outstanding B.Sc. (Hons') 1st class 1st merit position out of 40 successful students from the authority of Islamic University, Bangladesh. 

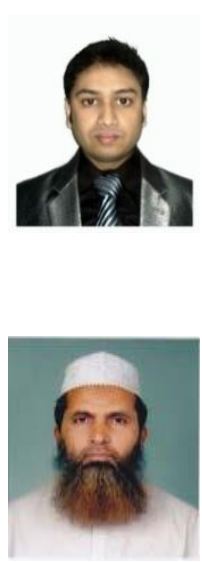

M. K. Rahman was born on July 1, 1971 in Madaripur, Bangladesh. He received the M.Sc. degree in Applied Physics, Electronics \& Communication Engineering from University of Dhaka, Bangladesh in 1992. He is currently a Professor in the department of Electrical and Electronic Engineering, Faculty of Applied Science \& Technology, Islamic University, Kushtia-7003, Bangladesh. His interest is in Optoelectronics and Wireless Communication. His work has produced nearly 20 national and international papers.

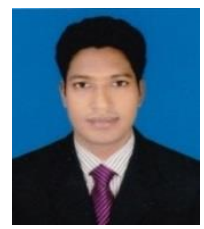

Sheikh Dobir Hossain is working as an Assistant Professor in the dept. of Physics at Jessore University of Science and Technology, Jessore-7408, Bangladesh. He holds the degree of B.Sc \& M.Sc in Electrical and Electronic Engineering from Islamic University, Kushtia-7003, Bangladesh. The fields of his research interest are intelligent systems design, wireless antenna design, wireless communication, and material science.

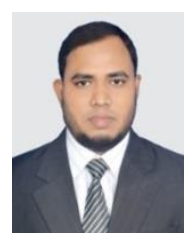

Md. Khalid Hossain has been received the B.Sc. (Hons) and M.Sc. degree in Applied Physics, Electronics \& Communication Engineering of Islamic University, Kushtia-7003, Bangladesh in 2008 and 2009 respectively. Currently he is working as a Scientific Officer in the Institute of Electronics, Atomic Energy Research Establishment (AERE), Bangladesh Atomic Energy Commission (BAEC), Savar, Dhaka-1349, Bangladesh. His current interests are advanced materials science, functional materials, photovoltaic devices, thin film, Micro/Nano fabrication, biosensor, intelligent systems design etc. He is the author/co-author of more than 20 international papers.

How to cite this paper: ASM Shamim Hasan, Md. Khalid Hossain Jewel, Md. Niaz Mostakim, Nabil Hossain Bhuiyan, M.K. Rahman, Sheikh Dobir Hossain, Md. Khalid Hossain,"Smartphone Controlled Spy Robot with Video Transmission and Object Collector", International Journal of Engineering and Manufacturing(IJEM), Vol.7, No.6, pp.50-58, 2017.DOI: 10.5815/ijem.2017.06.05 